Background Limited budget in road safety projects generate a need to seek alternative funding for road safety with such mechanism which enable to achieve expected outcomes of road safety programmes without giving additional costs to government and tax payers.

Methods The research strategy is exploratory of a number of documents which related with road safety programmes, road financing, road safety financing, and social investments.

Results Managing funding in road safety using business-like approach rather than a government's social responsibility is considered as second generation of road funds (Robinson, 2008; Brushett, 2005). There could be commercial style road safety organisation/council/committee with strong public support for better road safety management and affordable road financing (Heggie, 2003). Road safety could be improve significantly if the interventions are carried out since preventive area. Preventive area is mostly seen as a public good. To make preventive area attractive to private sectors is to see preventive area as a merit good. The interventions are intended to improve safety level in an area of high social need and supported by evidence of efficacy. Impacts of interventions could be measured accurately. There is a saving, particularly for government, because of lower cost of the interventions and transactions.

Conclusions The effective funding for road safety is affected by timing of the interventions. Interventions which are conducted at prevention stage will give great impacts, comparing with other stage of road safety. Thus, funding which intended for this stage will give effective results. Beside of timing, funding mechanism should consider involvement of private sectors with outcome orientation.

\section{SAFETY MANAGEMENT IN SEAPORTS AND LOGISTIC CHAIN AND CONTAINER GASES AS AN OCCUPATIONAL SAFETY RISK}

Anne E Suominen, Sari Nyroos, Johanna Yliskylä-Peuralahti. University of Turku, Brahea Centre/Centre for Maritime Studies, Finland

10.1136/injuryprev-2016-042156.756

Background Occupational safety management includes awareness and prevention of risky situations, and maintenance of safe working environment. From an occupational safety perspective a seaport contains several critical interfaces because it is a shared workplace where employees represent many different organisations. An occupational safety risk in seaports and logistics operations is fumigants used in goods transported in containers. Reports of health impairments suffered among persons who have opened fumigated containers are reported from several countries. Objective The use of fumigants is an appropriate way to protect goods during transport and storage. Problems arise when transport documents do not make any record of fumigation, the containers are not labelled with warnings, and the persons handling the containers are unaware of the health risks. It is thus critical to raise awareness of the health risks of fumigation and create preventive measures.

Results In our recent collaborative networks ("Work safety culture - port as a communal workplace", "National operation model and work safety protocol for prevention of container gas risks", "Cargo securing working group") we have contributed to the aims of increasing awareness of occupational safety risks at seaports and the importance of shared safety culture by producing easy-to-access learning material and occupational safety guidelines; by inviting different authorities and stakeholder organisations to collaborative workshops to discuss the risks, prevention methods and best practices; and by enhancing international collaboration and information sharing.

Conclusions Sharing information about fumigation and cargo securing risks, and creation of a shared safety culture in collaboration between the different organisations that are involved in handling containers and the goods they contain are critical issues for safety in logistic operations.

\section{CONSENCUS AND CONFLICT MODELS IN HEALTH POLICY MAKING}

Bjarne Jansson. Karolinska Institutet, Department of Public Health Sciences, KI Campus, 17176

\subsection{6/injuryprev-2016-042156.757}

Implementation of the WHO Safe Community Program at local level includes an equity approach. Of interest is therefore, how well typologies on community organisation consider the needs for vulnerable and deprived groups in the community. Several models have been developed and implemented. Newer refined models have to consider problems in a multicultural context to a greater extent. Power, empowerment and critical consciousness are central concepts in community organising. Top-down models does not fully serve the interest of safety among deprived and expelled groups. One way is to make conflicts of interest much more transparent. Instead of consencus models a model based on Alinsky's conflict model "social action" could better challenge the conflicts of interest in the community.

\section{SYSTEMATIC SAFETY AND SECURITY RISK MANAGEMENT ON FARMS}

Jarkko Leppälä. Natural Resources Institute Finland (Luke)

\subsection{6/injuryprev-2016-042156.758}

Background The problems and risks are diverse in farming, which threaten safety and security on farms. Currently, there is little information how farm safety and security management is integrated into management on farms. The objective in this $\mathrm{PhD}$ study was to increase the understanding of systematic safety and security risk management applied to farms. Special attention was paid to the usability of risk management, the effectiveness of safety and security risk management, and the sustainability management on farms. Farm business security risks are risks, which threat the business continuity and sustainability on farms. These farm security risks include food production safety risks like human and animal diseases, farm economic crisis, water pollution and eutrophication caused by farming, asset risks like fire accidents, water and energy interruptions and farmers' serious occupational health problems all have exacerbated the special importance of risk management on farms. More information is needed on farm business continuity and supporting farms in systematic risk management as a holistic and practical manner. This dissertation presents new tools and applications for systematic risk management on farms.

Methods The study was a mixed method research. Systematic review of the literature, two surveys and case studies were conducted to identify safety and security risk management approaches in agriculture. Risk management aspects of a national 
health and safety program were evaluated, and farm-level tools were developed to improve safety and security management on farms.

Results As a result of the study new implication describing the farm manager's various tasks and the farm safety and security risk management approach is presented. The results point out the need for systematic risk management approach in farm safety management. The findings indicate that safety risks were connected to other management risks on farms. Injury risk were significantly connected to animal (vs. crop) production, larger farm size (field and herd size), dependence on one person, physical work strain, perceived fire risk, and infrastructural problems on farms. Regular monitoring of safety and security risks was protective against injury incidents. A contextual tool for preliminary farm risk identification, a Farm Risk Map, was constructed and tested.

Conclusions Mitigation of farm safety and security risks requires specific management tools and occupational skills applied to agriculture. Risk management tools to assist farmers are not currently in a sufficient level compared to safety and security risks faced by farmers. The Farm Risk Map helped the case farmers to visualise and identify major risk sources affecting the farm operations. It can be used to define the risk context on farms. Additional tools to assist managing and controlling major farm risk areas were presented. Improved knowledge management skills and holistic risk management tools are needed on farm risk management in the future.

\section{Traffic Safety}

\section{Post Tue 2.16}

\section{ROAD LIGHTING AND SAFETY: A PILOT STUDY OF ARTHABASKA REGION}

Mustafa Aldulaimi, Luis AmadorJimenez. Concordia University, Canada

10.1136/injuryprev-2016-042156.759

Background We investigate the specification of roadway lighting for safety to understand the elements needed in statistical analysis of road collisions during night time. Several goals were targeted. First, which type of response is best, or whether both responses should be used. Second, which indicator of lighting should we favour? Third, which other factors should be included in the analysis and fourth, how effective is lighting in reducing nightime collision.

Methods The case study comprised illuminance and luminance measurements collected for the Arthabaska region in Quebec, along with available operational and geometric variables expected to explain roadway collisions. A zero-inflated negative-binomial model was used to analyse the impact of predictors on collision frequency and severity using classical maximum likelihood validated by a Full Bayesian regression

Results It was found that collision severity is best, resulting in more factors being significant in the expected sense of contribution. Luminance was the best indicator for road lighting. A correlation matrix aided in the identification of linearly dependencies between factors and the response or other factors. The last goal was investigated by comparing daytime with night-time collision analysis. The night time analysis included luminance and glare. The results were very close between day and night, with luminance proving to be an effective countermeasure for night collisions. A three-times difference on the coefficient for traffic volume was found. The use of a dummy variable related to standard levels of illumination is presented and will be key in future research for the estimation of effective levels of lighting.

Conclusions A connexion between roadway lighting and crash history can be used to support the warrant of lighting and identification of levels by using the statistical methods herein proposed adapted to test effectiveness of lighting levels and explanatory power of variables surviving co-linearity and significance tests.

\section{PREDICTING AND ANALYSING THE TREND OF DEATH CAUSED BY TRAFFIC ACCIDENTS IN IRAN IN 2014 AND 2015}

1,2Mohammadreza Mehmandar, ${ }^{1}$ Hamid Soori, ${ }^{3}$ Yadolah Mehrabi. ' Safety Promotion and Injury Prevention Research Centre of Shahid Beheshti University of Medical Sciences, Tehran, Iran; ${ }^{2}$ Rahvar Research Centre, Traffic Police of Iran; ${ }^{3}$ Health School of Shahid Beheshti University of Medical Sciences

\subsection{6/injuryprev-2016-042156.760}

Background Predicting the death trend caused by traffic accidents and its analysis is a useful tool for planning and policy-making by the authorities in the field of road traffic, conducting interventions appropriate with death trend, and taking the actions required for controlling future conditions.

Methods In a cross-sectional research, all the information related to the traffic accidents leading to death available in the database of Iran Legal Medicine Organisation from 2004 to the end of 2013 was used to determine the change points (multi-variable time series analysis). Role of regulations and rules in the variations of death caused by traffic load was studied using Box Jenkins multi-variable time series models and critical path analysis (CPA) over time. Using autoregressive integrated moving average (ARIMA) model, rate of death caused by traffic accidents was predicted for 2014 and 2015 and, finally, the actual rate of death caused by traffic accidents was compared with the predicted value to determine the efficiency of the model.

Results Results showed that rate of death in 2014 was almost equal to the actual rate of death recorded for this year, while rate of death in 2015 decreased compared with the previous year (2014) during all months. It was also predicted that, in January and February 2015, rate of death would reach its minimum value in that year, i.e. $4.1 \%$.

Conclusions According to the prediction and analysis of the trend of death caused by traffic accidents, it was observed that applying and continuing the intervention conducted in the previous years for road safety improvement, motor vehicle safety improvement, particularly training and culture-fostering interventions, as well as approval and execution of deterrent regulations for changing the organisational behaviours can significantly decrease the loss caused by traffic accidents.

\section{FIRST STEPS IN ENDORSING TRAFFIC SAFETY AMONG EMPLOYEES IN FINLAND}

Antero Lammi, Laura Vainiomäki. Finnish Traffic Safety Council, Finland

\subsection{6/injuryprev-2016-042156.761}

Background Time spent on commuting is the most dangerous time of the workday. Over two million Finnish people commute on daily basis and $80 \%$ of the commuting accidents occur as pedestrians or by bicycle. Contacting working-aged people has 